\title{
Floating septum technique: easy and safe method maxillary sinus septa in sinus lifting procedure
}

\author{
Junho Jung ${ }^{1,2+}$, Bo-Yeon Hwang ${ }^{1,2+}$, Byung-Soo Kim² and Jung-Woo Lee ${ }^{1,2^{*}}$
}

\begin{abstract}
Background: The presence of septa increases the risk of Schneiderian membrane perforation during sinus lift procedure, and therefore, the chance of graft failure increases. We present a safe method of managing septa and, in particular, overcoming small and palatally located septa.

Methods: After the elevation of the flap and the creation of a small bony window positioned anterior to the septum, the Schneiderian membrane is lifted carefully. A thin and narrow osteotome is then placed at the indentation created at the base of the septum, and mobilization of the septum is achieved by gentle malleting. The membrane is again carefully lifted up behind the septum.

Results: There was one small membrane perforation case in all 16 cases, and none of these patients showed postoperative complications such as implant failure, infection, or maxillary sinusitis.

Conclusions: This technique is useful for overcoming the problem of maxillary sinus septa hindering the sinus floor elevation procedure, leading to fewer complications.
\end{abstract}

Keywords: Maxillary sinus, Sinus elevation, Septum

\section{Background}

Sinus lift is a popular method for the placement of dental implants in the atrophic posterior maxillary area. Various causes of Schneiderian membrane perforation have been reported [1], and the presence of septa increases the risk of Schneiderian membrane perforation during this procedure, and therefore, the chance of graft failure increases. The prevalence of maxillary septa is reported to be $7.1-58.3 \%$ [2], which is too high to ignore. As expected, the frequency of perforation is higher in the presence of septa (42.9\%) than in the absence of septa $(23.8 \%)$ [3]. Various approaches to overcome the increased risk of perforation in the presence of septa have been proposed $[4,5]$. However, these methods involve making wider windows to elevate the membrane

\footnotetext{
* Correspondence: omsace@khu.ac.kr

†unho Jung and Bo-Yeon Hwang contributed equally to this work

${ }^{1}$ Department of Oral and Maxillofacial Surgery, School of Dentistry, Kyung Hee University, 26, Kyungheedae-ro, Dongdaemun-gu, 02447 Seoul, Republic of Korea

${ }^{2}$ Department of Oral and Maxillofacial Surgery, Kyung Hee University Dental Hospital, Seoul, Republic of Korea
}

\section{Methods \\ Surgical technique}

A crestal incision is made with a vertical releasing incision on the mesial and distal sides. The flap is then subperiosteally elevated. It is sufficient to create a single small window. The distal margin of the bony window is positioned anterior to the septum or extended distally to include the septum. The size of the bony window should be large enough to allow access of the sinus lifting instruments used to elevate the membrane.

Subsequently, the Schneiderian membrane is lifted carefully on all sides except at the septum. After this preparation is complete, a linear indentation with a round bur or piezoelectric instrument is made at the base of the septum. A thin and narrow osteotome is then placed at the indentation (Fig. 1). To avoid tearing 


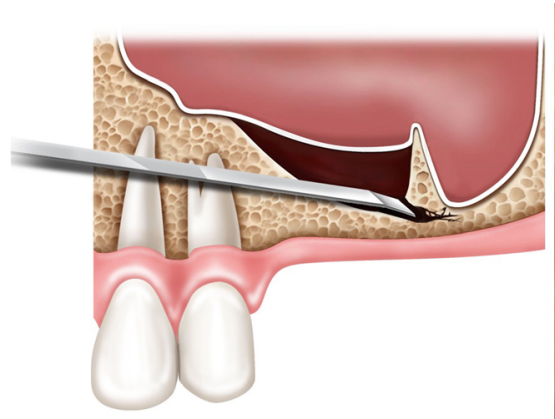

(A)

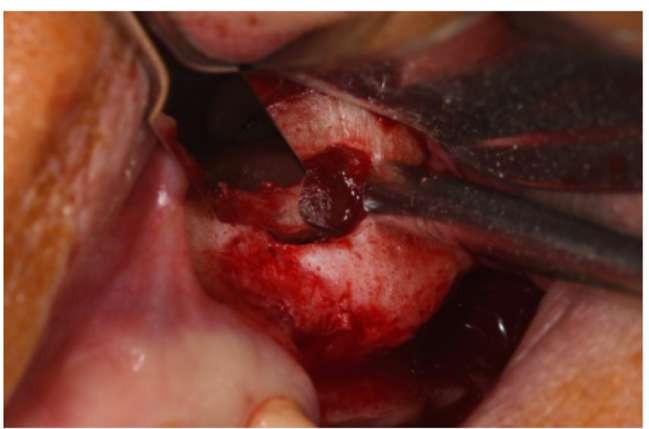

(B)

Fig 1 a A schematic image of the floating septum technique. $\mathbf{b}$ A clinical photograph showing the application of a thin and narrow osteotome after the creation of bony window and the elevation of Schneiderian membrane

the membrane, osteotomy should be performed with gentle malleting. Mobilization of the septum is achieved and the membrane is again carefully lifted up behind the septum. The septum is now floating along with the membrane. Removal of the septum is not recommended, as this can cause an undesirable perforation. The Schneiderian membrane should then be macroscopically inspected and the graft material inserted.

\section{Results}

We have operated on 16 patients (16 sides) (Table 1 ). There were eleven men and five women, mean (SD) age was 53.63 (8.94) years. All patients received the installation of dental implants and sinus lifting procedure simultaneously. Only one patient had a small Schneiderian membrane perforation which was repaired with BioGide (Geistlich Pharma AG ${ }^{\circ}$, Wolhusen, Switzerland), and none of these patients showed postoperative complications such as implant failure, infection, or maxillary sinusitis.

\section{Discussion}

We obtained a favorable result with the method described herein, although further studies with larger sample sizes are required to validate our result. This technique only requires one small window, which means shorter operation times, decreased surgical discomfort, and better bony in-growth to the grafted area. In addition, since this method does not involve crossing the instrument tip of the septum, the risk of tearing the

Table 1 Patients' details

\begin{tabular}{|c|c|c|c|c|c|c|}
\hline Case no. & Age (years) & Sex & Dental implants & Surgery & Septum management & Complications \\
\hline 1 & 58 & $M$ & $\# 14,15,16,17$ & $\mathrm{SL}+\mathrm{DI}+\mathrm{GBR}$ & $\mathrm{O}$ & No \\
\hline 2 & 63 & $\mathrm{~F}$ & \#26 & $S L+D I$ & $\mathrm{O}$ & No \\
\hline 3 & 68 & M & $\# 26,27$ & $S L+D I$ & $\mathrm{O}$ & No \\
\hline 4 & 46 & M & \#26 & $\mathrm{TE}+\mathrm{SL}+\mid \mathrm{IDI}$ & $\mathrm{O}$ & No \\
\hline 5 & 64 & M & $\# 15,16,17$ & $S L+D I$ & $\mathrm{O}$ & No \\
\hline 6 & 42 & M & $\# 16$ & $\mathrm{TE}+\mathrm{SL}+\mid \mathrm{IDI}$ & $\mathrm{O}$ & No \\
\hline 7 & 46 & $\mathrm{~F}$ & $\# 26,27$ & $S L+D I$ & $\mathrm{O}$ & No \\
\hline 8 & 46 & M & $\# 26,27$ & $S L+D I$ & O & No \\
\hline 9 & 64 & M & $\# 16,17$ & $S L+D I$ & $\mathrm{O}$ & Membrane perforation \\
\hline 10 & 56 & $\mathrm{~F}$ & $\# 15,16,17$ & $\mathrm{SL}+\mathrm{DI}+\mathrm{GBR}$ & $\mathrm{R}+\mathrm{O}$ & No \\
\hline 11 & 48 & M & $\# 26,27$ & $S L+D I$ & $\mathrm{R}+\mathrm{O}$ & No \\
\hline 12 & 65 & $\mathrm{~F}$ & $\# 26,27$ & $S L+D I$ & $\mathrm{R}+\mathrm{O}$ & No \\
\hline 13 & 45 & $\mathrm{~F}$ & $\# 16$ & $\mathrm{TE}+\mathrm{SL}+|\mathrm{DI}|$ & $P+O$ & No \\
\hline 14 & 55 & M & $\# 26,27$ & $S L+D I$ & $P+O$ & No \\
\hline 15 & 45 & M & $\# 26,26$ & $S L+D I$ & O & No \\
\hline 16 & 47 & $M$ & $\# 26,27$ & $S L+D I$ & $P+O$ & No \\
\hline
\end{tabular}

$M$ male, $F$ female, $S L$ sinus lift, $D I$ dental implants, GBR guided bone regeneration, $T E$ tooth extraction, IDI immediate dental implant installation, $O$ osteotom, $R$ round bur, $P$ piezoelectric instrument 
membrane is also decreased. This method was useful for managing the septum in the maxillary second molar region and immediate implant placement after maxillary molar extraction, which were quite challenging with the conventional method.

\section{Conclusion}

We postulate that this technique is useful for overcoming the problem of maxillary sinus septa hindering the sinus floor elevation procedure, leading to fewer complications.

\section{Acknowledgements}

Not applicable

\section{Authors' contributions}

$\mathrm{BYH}, \mathrm{BSK}$, and $\mathrm{JHJ}$ performed the procedure, designed the study, and subsequently clinically verified by all authors. BYH, JHJ, and JWL wrote the manuscript. BYH and $\mathrm{JHJ}$ contributed equally to this manuscript as the first author. All authors read and approved the final manuscript.

\section{Funding}

This research was supported by the Bio \& Medical Technology Development Program of the National Research Foundation (NRF) and funded by the Korean government (MSIP\&MOHW) (No. 2017M3A9E4048170).

Availability of data and materials

Not applicable

\section{Ethics approval and consent to participate}

Ethics approval was not required. Information of the patient has all been anonymized.

\section{Consent for publication}

This manuscript does not contain any individual person's identifier (including individual details, images, or videos).

\section{Competing interests}

The authors declare that they have no competing interests.

Received: 30 July 2019 Accepted: 3 October 2019

Published online: 28 November 2019

\section{References}

1. Jordi C, Mukaddam K, Lambrecht JT, Kuhl S (2018) Membrane perforation rate in lateral maxillary sinus floor augmentation using conventional rotating instruments and piezoelectric device-a meta-analysis. Int J Implant Dent 4:3

2. Pommer B, Ulm C, Lorenzoni M, Palmer R, Watzek G, Zechner W (2012) Prevalence, location and morphology of maxillary sinus septa: systematic review and meta-analysis. J Clin Periodontol 39:769-773

3. von Arx T, Fodich I, Bornstein MM, Jensen SS (2014) Perforation of the sinus membrane during sinus floor elevation: a retrospective study of frequency and possible risk factors. Int J Oral Maxillofac Implants 29:718-726

4. Betts NJ, Miloro M (1994) Modification of the sinus lift procedure for septa in the maxillary antrum. J Oral Maxillofac Surg 52:332-333

5. Sailer HF (1989) A new method of inserting endosseous implants in totally atrophic maxillae. J Craniomaxillofac Surg. 17:299-305

\section{Publisher's Note}

Springer Nature remains neutral with regard to jurisdictional claims in published maps and institutional affiliations.

\section{Submit your manuscript to a SpringerOpen ${ }^{\circ}$ journal and benefit from:}

- Convenient online submission

- Rigorous peer review

- Open access: articles freely available online

- High visibility within the field

- Retaining the copyright to your article 